\title{
Value of saliva testing when added to questionnaire screening for unhealthy drug use
}

\author{
H John Saade ${ }^{1 *}$, Anthony Dedea ${ }^{1}$, Lauren Dedea', Jason Dhabliwala ${ }^{1}$, Andrea T Pusser $^{1}$, J Aaron Johnson², \\ J Paul Seale \\ From INEBRIA 12th Congress, \\ Atlanda, GA, USA. 24-25 September 2015
}

\section{Background}

Unhealthy drug use (UDU), including both illicit drug use and misuse of prescription medications, is high among Americans 12 or older (9.4\% past month; $48 \%$ lifetime), and is often $50-100 \%$ higher among emergency department (ED) patients (Cherpitel \& Ye, 2008). While most screening, brief intervention and referral to treatment (SBIRT) projects focus on questionnaire screening for UDU, many clinicians are unaware of the potential of saliva testing (ST) to increase detection.

The objective is toassess the added value of ST when added to comprehensive questionnaire screening for UDU.

\section{Material and methods}

Research assistants systematically approached adult patients receiving care in the medical-surgical area of an urban ED. After granting informed consent, patients completed a survey containing four different single-item drug screening questions (SDSQs) and the drug use section of the Mini International Neuropsychiatric Interview, then received a financial incentive. Patients granting separate consent then provided a saliva sample for drug testing and received a second incentive.

\section{Results}

Among 208 patients interviewed, only 111 (53.4\%) agreed to saliva testing. Nine samples were positive in patients not reporting illegal/recreational drug use. Six were positive for prescribed medications which they had reported (five for alprazolam, one for opioids). Two were positive for undisclosed cocaine. One was positive

\footnotetext{
* Correspondence: saade.hanna@navicenthealth.org

'Department of Family Medicine, Navicent Health/Mercer University School of Medicine, Macon, GA, USA

Full list of author information is available at the end of the article
}

for barbiturates in a patient who did not report barbiturate use.

\section{Conclusions}

ST detected two patients (1.8\% of those submitting samples) with unsuspected illicit drug use and one patient (0.9\%) with unreported prescription psychotropic drug use. Despite financial incentives, $47 \%$ of patients refused ST, which could have disclosed more unreported drug use. Results confirm the ability of biomarker testing to detect small numbers of additional patients with potentially life-threatening UDU when added to questionnaire screening.

\section{Acknowledgements \\ This study was funded by Grant \# TI019545 from the Substance Abuse and Mental Health Services Administration (SAMHSA), USA. The authors also wish to acknowledge the assistance from all the faculty and staff at the Family Health Center, Macon, GA, USA with especial appreciation to the Behavioral Sciences Department.}

\section{Authors' details}

'Department of Family Medicine, Navicent Health/Mercer University School of Medicine, Macon, GA, USA. ${ }^{2}$ Institute of Public and Preventive Health, Georgia Regents University, Augusta, GA, USA.

Published: 24 September 2015

Reference

1. Cherpitel CJ, Ye Y: Drug use and problem drinking associated with primary care and emergency room utilization in the US general population: data from the 2005 national alcohol survey. Drug alcohol depend 2008, 97:226-230.

doi:10.1186/1940-0640-10-S2-O25

Cite this article as: Saade et al:: Value of saliva testing when added to questionnaire screening for unhealthy drug use. Addiction Science \& Clinical Practice 2015 10(Suppl 2):O25.
Ciomed Central

C 2015 Saade et al. This is an Open Access article distributed under the terms of the Creative Commons Attribution License (http:// creativecommons.org/licenses/by/4.0), which permits unrestricted use, distribution, and reproduction in any medium, provided the original work is properly cited. The Creative Commons Public Domain Dedication waiver (http://creativecommons.org/publicdomain/ zero/1.0/) applies to the data made available in this article, unless otherwise stated. 